\title{
PENGENALAN POLA HURUF DENGAN MENGGUNAKAN ALGORITMA ADALINE
}

\author{
Bety Etikasari ${ }^{1}$, Trismayanti Dwi Puspitasari ${ }^{2}$ \\ 1),2) Teknologi Informasi, Politeknik Negeri Jember \\ Jl. Mastrip POBOX 164 Jember \\ bety.etikasari@gmail.com
}

\begin{abstract}
ABSTRAK
Bidang kecerdasan buatan merupakan salah satu bidang teknologi yang menjadikan perubahan kehidupan manusia semakin berkembang kearah memudahkan aktivitas manusia karena kecerdasan manusia berkonsep pada pikiran cerdas manusia. Penelitian bidang kecerdasan buatan pada permasalahan penyandang disabilitas memberikan manfaat kemudahan dalam aksesibilitas kebutuhan sehari-hari. Salah satu permasalahan yang terjadi pada penyandang disabilitas adalah terkait pengenalan huruf misalnya dalam menulis. Penyelesaian untuk permasalahan tersebut adalah dengan pembuatan aplikasi pengenalan pola huruf. Salah satu algoritma yang digunakan dalam kasus pengenalan pola adalah algoritma Adaline. Penelitian ini bertujuan untuk menentukan perhitungan yang efektif dari algoritma Adaline untuk pengenalan pola huruf agar dapat dijadikan acuan dalam pengembangan aplikasi pengenalan pola huruf. Penerapan pelatihan Adaline akan efektif untuk diterapkan dalam pengembangan aplikasi pengenalan pola huruf apabila nilai alfa yang diperkecil yaitu 0,05 , nilai toleransi yang diperbesar yaitu 0,1 dan menggunakan fungsi aktivasi bipolar.
\end{abstract}

Keyword : pelatihan adaline, nilai alfa, nilai toleransi, fungsi aktivasi bipolar, pengenalan pola huruf .

\section{PENDAHULUAN}

Bidang kecerdasan buatan merupakan salah satu bidang teknologi yang menjadikan perubahan kehidupan manusia semakin berkembang kearah memudahkan aktivitas manusia karena kecerdasan manusia berkonsep pada pikiran cerdas manusia. Penelitian bidang kecerdasan buatan pada permasalahan penyandang disabilitas memberikan manfaat kemudahan dalam aksesibilitas kebutuhan sehari-hari. Salah satu permasalahan yang terjadi pada penyandang disabilitas adalah terkait pengenalan huruf misalnya dalam membaca sebuah kalimat. Penyelesaian untuk permasalahan tersebut adalah dengan pembuatan aplikasi pengenalan pola huruf. Salah satu algoritma yang digunakan dalam kasus pengenalan pola adalah algoritma Adaline.

Jaringan Syaraf Tiruan (JST) merupakan salah satu upaya manusia untuk memodelkan cara kerja atau fungsi sistem syaraf manusia dalam melaksanakan tugas tertentu. Pemodelan ini didasari oleh kemampuan otak manusia dalam mengorganisasikan sel-sel penyusunnya yang disebut neuron, sehingga mampu melaksanakan tugas-tugas tertentu, khususnya pengenalan pola dengan efektivitas yang sangat tinggi [1]. Terdapat berbagai metode dalam JST salah satunya adalah algoritma pelatihan Adaptive Linier Neuron (Adaline). Adaline digunakan dalam pengenalan pola karena merupakan perbaikan dari metode perceptron. Algoritma adaline memperbaikinya dengan memodifikasi bobot dengan menggunakan aturan Least Mean Square. Adaline menggunakan dua pengubahan pada laju pemahaman dan batas toleransi sehingga lebih efektif dalam pengenalan pola yang dilakukan. Hal ini didukung oleh beberapa penelitian dan pengembangan yang dilakukan oleh beberapa peneliti.

Penelitian dan pengembangan sistem pakar untuk diagnosa penyakit ginjal dengan jaringan syaraf tiruan adaline. Hasil penelitian menyimpulkan bahwa perangkat lunak sistem pakar diagnosa penyakit ginjal ini mampu membantu pengguna dalam diagnosa penyakit ginjal dan memberikan solusi awal yang harus dilakukan [2]. Selanjutnya, penelitian dan pengembangan sistem pendeteksian wajah pada video menggunakan jaringan adaptive linier neuron atau adaline. Hasil penelitian menyimpulkan bahwa sistem pendeteksi wajah menggunakan pendekatan jaringan adaline dengan algoritma belajar memiliki detection rate berkisar dari $65 \%$ hingga $90 \%$ sehingga adaline memiliki kemampuan pengenalan pola wajah dengan jumlah data pelatihan yang tidak terlalu besar dan sangat tepat untuk diterapkan pada sistem biometriks yang membutuhkan proses pendeteksi wajah [3].

Model Adaline ditemukan oleh Widrow dan Hoff (1960). Arsitekturnya mirip dengan perceptron. Beberapa masukan (dan sebuah bias) dihubungkan langsung dengan sebuah neuron keluaran. Perbedaan dengan perceptron adalah cara modifikasi bobot [4]. Bobot dimodifikasi dengan aturan DELTA (Least Mean Square). Selama pelatihan, fungsi aktivasi yang dipakai adalah fungsi identitas.

$$
\begin{aligned}
& n e t=\sum_{i} x_{i} w_{i}+b \ldots \ldots \ldots \ldots \ldots \ldots \ldots \\
& \boldsymbol{y}=\boldsymbol{f}(\boldsymbol{n e t})=\boldsymbol{n e t}=\sum_{\boldsymbol{i}} \boldsymbol{x}_{\boldsymbol{i}} \boldsymbol{w}_{\boldsymbol{i}}+\boldsymbol{b} \ldots \ldots \ldots
\end{aligned}
$$


Kuadrat selisih antara target (t) dan keluaran jaringan (f(net)) merupakan error yang terjadi. Dalam aturan delta, bobot dimodifikasi sedemikian hingga errornya minimum.

$$
E=(t-f(n e t))^{2}=\left(t-\left(\sum_{i} x_{i} w_{i}+b\right)\right)^{2}
$$

E merupakan fungsi bobot $\mathrm{w}_{\mathrm{i}}$. Penurunan E tercepat terjadi pada arah

$\frac{\delta E}{\delta w_{i}}=-2\left(t-\left(\sum_{i} x_{i} w_{i}+b\right)\right) x_{i}=-2(t-y) x_{i}$

maka perubahan bobot adalah:

$\Delta w_{i}=\alpha(t-$

y) $x_{i}$

$\alpha$ merupakan bilangan positif kecil (umumnya diambil 0.1)
Arsitektur Adaline menggunakan arsitektur jaringan layar tunggal (single layer network) dapat dilihat pada Gambar 1.

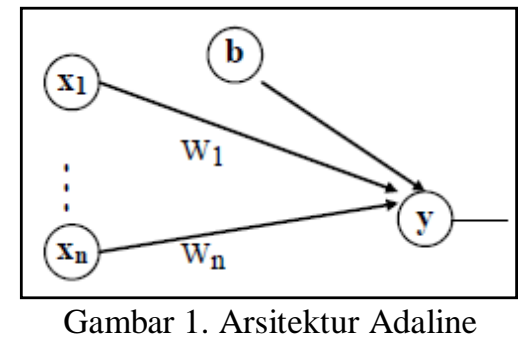

\section{PEMBAHASAN}

\subsection{Inisialisasi Pola Huruf}

Studi kasus pola yang digunakan dalam adaline ini adalah huruf "P". Pola huruf ditunjukkan pada Tabel 1. Matriks yang digunakan untuk pengenalan pola adalah bentuk matriks $3 \times 3$.

Tabel 1. Inisialisasi matriks pengenalan pola

\begin{tabular}{|c|c|c|c|c|c|c|c|c|c|c|c|c|c|c|c|}
\hline $\begin{array}{c}\text { Pola } \\
\text { Huruf }\end{array}$ & \multicolumn{3}{|l|}{ Matriks } & \multicolumn{6}{|c|}{$\begin{array}{c}\text { Inisialisasi Matriks dengan } \\
\text { Fungsi Aktivasi Bipolar }\end{array}$} & \multicolumn{6}{|c|}{$\begin{array}{c}\text { Inisialisasi Matriks dengan } \\
\text { Fungsi Aktivasi Biner }\end{array}$} \\
\hline \multirow{3}{*}{$\mathrm{P}$} & $\mathrm{x} 1$ & & & 1 & 1 & 1 & $\mathrm{x} 1$ & & $x 3$ & 1 & 1 & 1 & $\mathrm{x} 1$ & $x 2$ & $x 3$ \\
\hline & $x 4$ & $\times 5$ & $x 6$ & 1 & 1 & 1 & $x 4$ & $x 5$ & $x 6$ & 1 & 1 & 1 & $x 4$ & $x 5$ & $x 6$ \\
\hline & $x 7$ & $x 8$ & $x 9$ & 1 & -1 & -1 & $x 7$ & $x 8$ & $x 9$ & 1 & 0 & 0 & $x 7$ & $x 8$ & $x 9$ \\
\hline \multirow{3}{*}{ K } & $\mathrm{x} 1$ & $x 2$ & $x 3$ & 1 & -1 & 1 & $x 1$ & $x 2$ & $x 3$ & 1 & 0 & 1 & $\mathrm{x} 1$ & $x 2$ & $x 3$ \\
\hline & $x 4$ & $\times 5$ & $x 6$ & 1 & 1 & -1 & $x 4$ & $x 5$ & $x 6$ & 1 & 1 & 0 & $x 4$ & $\times 5$ & $x 6$ \\
\hline & $x 7$ & $x 8$ & $x 9$ & 1 & -1 & 1 & $x 7$ & $x 8$ & $\times 9$ & 1 & 0 & 1 & x7 & x8 & $\times 9$ \\
\hline \multirow{3}{*}{$\mathrm{J}$} & $\mathrm{x} 1$ & $x 2$ & $x 3$ & -1 & -1 & 1 & x1 & $x 2$ & & 0 & 0 & 1 & $\mathrm{x} 1$ & $x 2$ & $x 3$ \\
\hline & $x 4$ & $x 5$ & $x 6$ & -1 & -1 & 1 & $x 4$ & $x 5$ & $x 6$ & 0 & 0 & 1 & $x 4$ & $x 5$ & $x 6$ \\
\hline & $x 7$ & $x 8$ & $x 9$ & -1 & 1 & 1 & $x 7$ & $x 8$ & $x 9$ & 0 & 1 & 1 & $x 7$ & $\mathrm{x} 8$ & $x 9$ \\
\hline \multirow{3}{*}{$\mathrm{T}$} & $\mathrm{x} 1$ & $x 2$ & x3 & 1 & 1 & 1 & $\mathrm{x} 1$ & $x 2$ & $x 3$ & 1 & 1 & 1 & $\mathrm{x} 1$ & $x 2$ & $x 3$ \\
\hline & $x 4$ & $\times 5$ & x6 & -1 & 1 & -1 & $x 4$ & $\times 5$ & x6 & 0 & 1 & 0 & $\times 4$ & $\times 5$ & $x \in$ \\
\hline & $x 7$ & $x 8$ & $x 9$ & -1 & 1 & -1 & $x 7$ & $x 8$ & $x 9$ & 0 & 1 & 0 & $x 7$ & $x 8$ & $x 9$ \\
\hline \multirow{3}{*}{ I } & $\mathrm{x} 1$ & $x 2$ & $x 3$ & -1 & 1 & -1 & $\mathrm{x} 1$ & $x 2$ & $x 3$ & 0 & 1 & 0 & $\mathrm{x} 1$ & $x 2$ & $x 3$ \\
\hline & $x 4$ & $\times 5$ & x6 & -1 & 1 & -1 & x4 & $\times 5$ & x6 & 0 & 1 & 0 & $x 4$ & x5 & $x 6$ \\
\hline & x7 & x8 & x9 & -1 & 1 & -1 & $x 7$ & $x 8$ & $\times 9$ & 0 & 1 & 0 & x7 & x8 & $x 9$ \\
\hline
\end{tabular}




\subsection{Algoritma Adaline}

Penyelesaian pengenalan pola huruf dengan algoritma adaline sebagai berikut:

1. Inisialisasi semua bobot dan bias $\left(\mathrm{w}_{1} \mathrm{w}_{2}, \mathrm{w}_{3}, \mathrm{w}_{4}\right.$, $\mathrm{w}_{5}, \mathrm{w}_{6}, \mathrm{w}_{7}, \mathrm{w}_{8}, \mathrm{w}_{9}=\mathrm{b}=0$ ). Menentukan besar laju pemahaman $(\alpha)$ dan toleransi kesalahan yang diijinkan. Menentukan target.

2. Selama max $\Delta \mathrm{w}_{\mathrm{i}}>$ batas toleransi, maka lakukan:

a. Set aktivasi unit masukan $\mathrm{x}_{\mathrm{i}}$ dimana $(\mathrm{i}=1$ s/d 9) yaitu $x_{1}, x_{2}, x_{3}, x_{4}, x_{5}, x_{6}, x_{7}, x_{8}$, dan $\mathrm{X} 9$.

b. Hitung respon unit keluaran:

$$
\begin{aligned}
& \text { net }=\sum_{i} x_{i} w_{i}+b \ldots \ldots \\
& \mathrm{Y}=\mathrm{f}(\mathrm{net}) \ldots \ldots \ldots \ldots \ldots \\
& \Delta w_{i}=\alpha(t-y) x_{i} \\
& \text { dimana i adalah } 1 \mathrm{~s} / \mathrm{d} 9 .
\end{aligned}
$$

c. Perbaiki bobot pola yang mengandung kesalahan $(\mathrm{y} \neq \mathrm{t})$ menurut persamaan: $\mathrm{w}_{\mathrm{i}}($ baru $)=\mathrm{w}_{\mathrm{i}}($ lama $)+\alpha(\mathrm{t}-\mathrm{y}) \mathrm{x}_{\mathrm{i}}$ dimana $i$ adalah $1 \mathrm{~s} / \mathrm{d} 9$

$$
\mathrm{b}(\text { baru })=\mathrm{b}(\text { lama })+\alpha(\mathrm{t}-\mathrm{y}) \ldots \ldots
$$

Setelah proses pelatihan selesai, Adaline dapat digunakan untuk pengenalan pola. Caranya sebagai berikut:

1. Inisialisasi semua bobot dan bias dengan bobot dan bias dari hasil pelatihan

2. Untuk semua input masukan bipolar $\mathrm{x}$, lakukan:
1) Set aktivasi unit masukan masukan $x_{i}$ dimana (i= $1 \mathrm{~s} / \mathrm{d} 9$ ) yaitu $\mathrm{x}_{1}, \mathrm{x}_{2}, \mathrm{x}_{3}, \mathrm{x}_{4}, \mathrm{x}_{5}$, $\mathrm{x}_{6}, \mathrm{x}_{7}, \mathrm{x}_{8}$, dan $\mathrm{x}_{9}$

2) Hitung net vektor keluaran:

$$
n e t=\sum_{i} x_{i} w_{i}+b
$$

3) Kenakan fungsi aktivasi:

$$
\begin{aligned}
& f(x)= \begin{cases}1 & \text { jika } x \geq 0 \\
0 & \text { jika } x<0\end{cases} \\
& f(x)=\left\{\begin{array}{cc}
1 & \text { jika } x \geq 0 \\
-1 & \text { jika } x<0
\end{array}\right.
\end{aligned}
$$

Setalah tahapan proses pelatihan dan pengenalan pola selesai, maka dengan melihat pada fungsi aktivasi dapat diambil kesimpulan apabila $\mathrm{f}($ net $)=$ target maka pola yang diinginkan telah ketemu atau dikenali.

\subsection{Perhitungan pengenalan pola}

Penghitungan pengenalan pola huruf menggunakan nilai laju pemahaman $(\alpha)$ yaitu 0,05 ; 0,1 ; dan 0,2 dan batas toleransi 0,05 dan 0,1. Fungsi

\begin{tabular}{|c|c|c|c|c|c|c|c|c|c|c|c|c|c|c|}
\hline \multirow{2}{*}{ Pola } & \multicolumn{9}{|c|}{ Masukan } & \multirow{2}{*}{ bias } & \multirow{2}{*}{$\mathrm{t}$} & \multirow{2}{*}{ net } & \multirow{2}{*}{$Y=f($ net $)$} & \multirow{2}{*}{$t-y$} \\
\hline & $\mathrm{X} 1$ & $\mathrm{x} 2$ & $\mathrm{X} 3$ & $\mathrm{X} 4$ & $\mathrm{X5}$ & $\mathrm{X6}$ & $\mathrm{X7}$ & $\mathrm{X8}$ & $\mathrm{Xg}$ & & & & & \\
\hline & & & & & & & & & & & & \multicolumn{3}{|c|}{ Inisialisasi } \\
\hline $\mathrm{P}$ & 1 & 1 & 1 & 1 & 1 & 1 & 1 & -1 & -1 & 1 & 1 & 0.56 & 1 & 0.44 \\
\hline $\mathrm{K}$ & 1 & -1 & 1 & 1 & 1 & -1 & 1 & -1 & 1 & 1 & -1 & 1.05 & 1 & -2.05 \\
\hline 」 & -1 & -1 & 1 & -1 & -1 & 1 & -1 & 1 & 1 & 1 & -1 & 0.02 & 1 & -1.02 \\
\hline$T$ & 1 & 1 & 1 & -1 & 1 & -1 & -1 & 1 & -1 & 1 & -1 & 0.21 & 1 & -1.21 \\
\hline 1 & -1 & 1 & -1 & -1 & 1 & -1 & -1 & 1 & -1 & 1 & -1 & -1.00 & -1 & 0.00 \\
\hline
\end{tabular}
aktivasi yang digunakan yaitu bipolar dan biner.

\begin{tabular}{|c|c|c|c|c|c|c|c|c|c|}
\hline \multicolumn{10}{|c|}{ Perubahan Bobot } \\
\hline$\Delta w 1$ & $\Delta w / 2$ & $\Delta w_{3}$ & $\Delta w 4$ & $\Delta w 5$ & $\Delta w 6$ & $\Delta w 7$ & $\Delta w 8$ & $\Delta w 9$ & $\Delta b$ \\
\hline 0.09 & 0.09 & 0.09 & 0.09 & 0.09 & 0.09 & 0.09 & -0.09 & -0.09 & 0.09 \\
\hline-0.41 & 0.41 & -0.41 & -0.41 & -0.41 & 0.41 & -0.41 & 0.41 & -0.41 & -0.41 \\
\hline 0.20 & 0.20 & -0.20 & 0.20 & 0.20 & -0.20 & 0.20 & -0.20 & -0.20 & -0.20 \\
\hline-0.24 & -0.24 & -0.24 & 0.24 & -0.24 & 0.24 & 0.24 & -0.24 & 0.24 & -0.24 \\
\hline 0.00 & 0.00 & 0.00 & 0.00 & 0.00 & 0.00 & 0.00 & 0.00 & 0.00 & 0.00 \\
\hline
\end{tabular}

1. Kasus Pola "P" dengan fungsi aktivasi bipolar Pengenalan Pola Huruf P dengan nilai alfa 0,2 dan batas toleransi 0,05 . Hasil perhitungan Adaline dapat dilihat pada Tabel 2.

Tabel 2. Rangkuman hasil perhitungan Adaline dengan laju pemahaman $(\alpha)=0,2$ dan toleransi $=0,05$ menghasilkan epoch 13

\begin{tabular}{|c|c|c|c|c|c|c|c|c|c|}
\hline \multicolumn{10}{|c|}{ Bobot Baru } \\
\hline w1 & w/2 & w3 & w4 & w5 & w6 & w7 & w8 & w9 & b \\
\hline $\mathbf{0 . 3 2}$ & -0.03 & $\mathbf{0 . 2 1}$ & $\mathbf{0 . 0 9}$ & -0.03 & -0.01 & $\mathbf{0 . 0 9}$ & -0.09 & $\mathbf{0 . 0 3}$ & -0.14 \\
\hline 0.40 & 0.06 & 0.30 & 0.18 & 0.06 & 0.07 & 0.18 & -0.18 & -0.06 & -0.05 \\
\hline-0.01 & 0.47 & -0.11 & -0.23 & -0.35 & 0.48 & -0.23 & 0.23 & -0.47 & -0.46 \\
\hline 0.20 & 0.67 & -0.32 & -0.03 & -0.15 & 0.28 & -0.03 & 0.03 & -0.67 & -0.67 \\
\hline-0.04 & 0.43 & -0.56 & 0.21 & -0.39 & 0.52 & 0.21 & -0.21 & -0.43 & -0.91 \\
\hline-0.04 & 0.43 & -0.56 & 0.21 & -0.39 & 0.52 & 0.21 & -0.21 & -0.43 & -0.91 \\
\hline
\end{tabular}




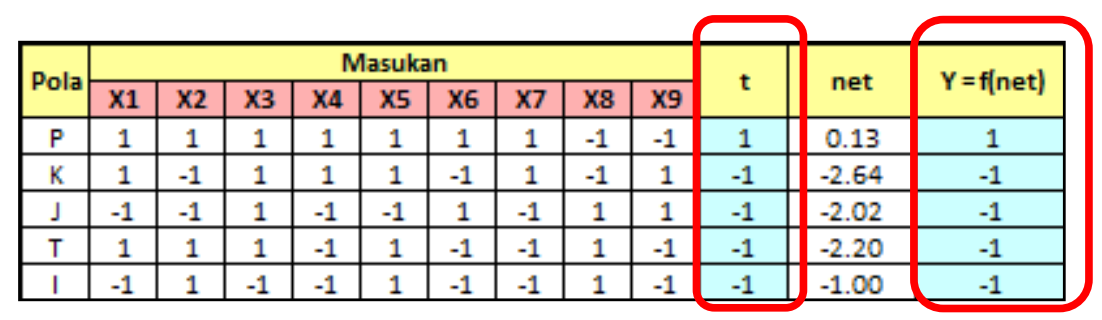

\section{Kesimpulan}

Dengan menggunakan model ADELINE untuk mengenali pola $\mathrm{P}$

dengan alpha 0.2 dan batas toleransi 0.05

iterasi dilakukan sampai Epoch 13

dapat dilihat melalui nilai $\mathrm{t}($ target $)=\mathrm{f}($ net $)$

2. Kasus Pola "P" dengan fungsi aktivasi biner

Pengenalan Pola Huruf $\mathrm{P}$ dengan nilai alfa 0,2 dan batas toleransi 0,05. Hasil perhitungan Adaline dapat dilihat pada Tabel 3.

Tabel 3. Rangkuman hasil perhitungan Adaline dengan laju pemahaman $(\alpha)=0,2$ dan toleransi $=0,05$ menghasilkan epoch 40

\begin{tabular}{|c|c|c|c|c|c|c|c|c|c|c|c|c|c|c|}
\hline \multirow{2}{*}{ Pola } & \multicolumn{9}{|c|}{ Masukan } & \multirow{2}{*}{ bias } & \multirow{2}{*}{$t$} & \multirow{2}{*}{ net } & \multirow{2}{*}{$Y=f($ net $)$} & \multirow{2}{*}{$t-y$} \\
\hline & $\mathrm{X} 1$ & $\mathrm{X} 2$ & $\mathrm{X3}$ & $\mathrm{X} 4$ & $\times 5$ & $\mathrm{X6}$ & $\mathrm{X7}$ & $\mathrm{X8}$ & $\times 9$ & & & & & \\
\hline & & & & & & & & & & & & \multicolumn{3}{|c|}{ Inisialisasi } \\
\hline$P$ & 1 & 1 & 1 & 1 & 1 & 1 & 1 & 0 & 0 & 1 & 1 & 1.00 & 1 & 0.00 \\
\hline $\mathrm{K}$ & 1 & 0 & 1 & 1 & 1 & 0 & 1 & 0 & 1 & 1 & 0 & 0.00 & 0 & 0.00 \\
\hline J & 0 & 0 & 1 & 0 & 0 & 1 & 0 & 1 & 1 & 1 & 0 & 0.00 & 1 & 0.00 \\
\hline$T$ & 1 & 1 & 1 & 0 & 1 & 0 & 0 & 1 & 0 & 1 & 0 & 0.00 & 0 & 0.00 \\
\hline 1 & 0 & 1 & 0 & 0 & 1 & 0 & 0 & 1 & 0 & 1 & 0 & 0.00 & 1 & 0.00 \\
\hline
\end{tabular}

\begin{tabular}{|c|c|c|c|c|c|c|c|c|c|c|}
\hline \multicolumn{10}{|c|}{ Perubahan Bobot } \\
\hline$\Delta w 1$ & $\Delta w 2$ & $\Delta w 3$ & $\Delta w 4$ & $\Delta w 5$ & $\Delta w 6$ & $\Delta w 7$ & $\Delta w 8$ & $\Delta w 9$ & $\Delta b$ \\
\hline 0.00 & 0.00 & 0.00 & 0.00 & 0.00 & 0.00 & 0.00 & 0.00 & 0.00 & 0.00 \\
\hline 0.00 & 0.00 & 0.00 & 0.00 & 0.00 & 0.00 & 0.00 & 0.00 & 0.00 & 0.00 \\
\hline 0.00 & 0.00 & 0.00 & 0.00 & 0.00 & 0.00 & 0.00 & 0.00 & 0.00 & 0.00 \\
\hline 0.00 & 0.00 & 0.00 & 0.00 & 0.00 & 0.00 & 0.00 & 0.00 & 0.00 & 0.00 \\
\hline 0.00 & 0.00 & 0.00 & 0.00 & 0.00 & 0.00 & 0.00 & 0.00 & 0.00 & 0.00 \\
\hline
\end{tabular}

\begin{tabular}{|c|c|c|c|c|c|c|c|c|c|}
\hline \multicolumn{10}{|c|}{ Bobot Baru } \\
\hline w1 & w2 & w3 & w4 & w5 & w6 & w7 & w8 & w9 & b \\
\hline-0.01 & $\mathbf{0 . 2 5}$ & $\mathbf{0 . 0 1}$ & $\mathbf{0 . 1 7}$ & -0.04 & $\mathbf{0 . 4 8}$ & $\mathbf{0 . 1 7}$ & -0.19 & -0.27 & -0.02 \\
\hline-0.01 & 0.25 & 0.01 & 0.17 & -0.04 & 0.48 & 0.17 & -0.19 & -0.27 & -0.02 \\
\hline-0.01 & 0.25 & 0.01 & 0.17 & -0.04 & 0.48 & 0.17 & -0.19 & -0.27 & -0.02 \\
\hline-0.01 & 0.25 & 0.01 & 0.17 & -0.04 & 0.48 & 0.17 & -0.19 & -0.27 & -0.02 \\
\hline-0.01 & 0.25 & 0.01 & 0.17 & -0.04 & 0.48 & 0.17 & -0.19 & -0.27 & -0.02 \\
\hline-0.01 & 0.25 & 0.01 & 0.17 & -0.04 & 0.48 & 0.17 & -0.19 & -0.27 & -0.02 \\
\hline
\end{tabular}

\begin{tabular}{|c|c|c|c|c|c|c|c|c|c|c|c|c|}
\hline \multirow{2}{*}{ Polala } & \multicolumn{10}{|c|}{ Masukan } & \multirow{2}{*}{ net } & \multirow{2}{*}{ Y=f(net) } \\
\cline { 2 - 12 } & $\mathbf{X} 1$ & $\mathbf{X} 2$ & $\mathbf{X} 3$ & $\mathbf{X} 4$ & $\mathbf{X} 5$ & $\mathbf{X 6}$ & $\mathbf{X 7}$ & $\mathbf{X 8}$ & $\mathbf{X 9}$ & & & \\
\hline $\mathrm{P}$ & 1 & 1 & 1 & 1 & 1 & 1 & 1 & 0 & 0 & 1 & 1.00 & 1 \\
\hline $\mathrm{K}$ & 1 & 0 & 1 & 1 & 1 & 0 & 1 & 0 & 1 & 0 & 0.00 & 1 \\
\hline $\mathrm{J}$ & 0 & 0 & 1 & 0 & 0 & 1 & 0 & 1 & 1 & 0 & 0.00 & 1 \\
\hline $\mathrm{T}$ & 1 & 1 & 1 & 0 & 1 & 0 & 0 & 1 & 0 & 0 & 0.00 & 0 \\
\hline $\mathrm{I}$ & 0 & 1 & 0 & 0 & 1 & 0 & 0 & 1 & 0 & 0 & 0.00 & 1 \\
\hline
\end{tabular}

\section{Kesimpulan}

Dengan menggunakan model ADELINE, fungsi aktivasi biner untuk mengenali pola $\mathrm{P}$ dengan Alfa 0.2 dan batas toleransi 0.05

iterasi dilakukan sampai Epoch 40 belum menemukan pola dapat dilihat melalui nilai $\mathrm{t}$ (target) $\neq \mathrm{f}($ net) 
Tabel 4. Perbandingan hasil epoch untuk fungsi aktivasi bipolar dan biner pola $\mathrm{P}$

\begin{tabular}{|c|c|c|c|c|c|c|c|}
\hline \multirow{2}{*}{ Pola P } & \multicolumn{3}{|c|}{ Bipolar } & \multicolumn{3}{c|}{ Biner } \\
\cline { 3 - 8 } & \multicolumn{3}{|c|}{ Alfa } & \multicolumn{3}{c|}{ Alfa } \\
\cline { 3 - 7 } & 0,05 & 0,1 & 0,2 & 0,05 & 0,1 & 0,2 \\
\hline \multirow{2}{*}{ Toleransi } & 0,05 & Epoch 1 & Epoch 2 & Epoch 13 & Epoch $\infty$ & Epoch $\infty$ & Epoch $\infty$ \\
\cline { 2 - 7 } & 0,1 & Epoch 1 & Epoch 1 & Epoch 1 & Epoch $\infty$ & Epoch $\infty$ & Epoch $\infty$ \\
\hline
\end{tabular}

Tabel 4 menunjukkan bahwa pengenalan pola menggunakan pelatihan adaline dengan fungsi aktivasi bipolar akan efektif jika nilai alfa yang digunakan adalah kecil dengan nilai toleransi besar. Hal ini ditunjukkan dengan nilai alfa $0,05=$ epoch 1 , nilai alfa $0,1=$ epoch 2 , dan nilai alfa $0,2=$ epoch 13 sehingga semakin kecil nilai alfa maka jumlah iterasi atau epoch yang dihasilkan semakin kecil yang mengakibatkan pola akan lebih cepat dikenali. Namun, sebaliknya untuk nilai toleransi. Hal ini ditunjukkan dengan nilai toleransi 0,05 menghasilkan epoch dengan jumlah lebih besar yaitu sampai 13 epoch dibandingkan nilai toleransi 0,1 yang rata-rata menghasilkan jumlah epoch 1 sehingga semakin besar nilai toleransi maka jumlah iterasi atau epoch yang dihasilkan semakin kecil yang mengakibatkan pola akan lebih cepat dikenali. Sedangkan, pengenalan pola menggunakan pelatihan adaline dengan fungsi aktivasi biner tidak efektif untuk mengenali pola baik menggunakan nilai alfa $0,05,0,1$, dan 0,2 maupun nilai toleransi 0,05 dan 0,1 . Hal ini ditunjukkan dengan jumlah epoch yang dihasilkan adalah tah hingga $(\infty)$.

Berdasarkan hasil perbandingan jumlah epoch yang dihasilkan dari pelatihan Adaline pada Tabel 4 baik menggunakan fungsi aktivasi bipolar maupun fungsi aktivasi biner dapat disimpulkan bahwa pelatihan adaline akan efektif digunakan untuk pengenalan pola apabila menggunakan fungsi aktivasi bipolar. Hal ini seperti yang ditunjukkan pada Tabel 4, fungsi aktivasi bipolar menghasilkan jumlah epoch yang rendah sehingga cepat mengenali pola, sedangkan fungsi aktivasi biner menghasilkan jumlah epoch yang tak terhingga sehingga tidak dapat mengenali pola [5].

\section{KESIMPULAN}

Berdasarkan hasil perhitungan algoritma Adaline untuk pengenalan pola huruf, maka dapat disimpulkan sebagai berikut:

a. Semakin kecil nilai alfa yang digunakan dalam pelatihan adaline untuk pengenalan pola huruf
"P" maka semakin kecil pula jumlah epoch yang dihasilkan sehingga pola lebih cepat dikenali.

b. Semakin besar nilai toleransi yang digunakan dalam pelatihan adaline untuk pengenalan pola huruf "P" maka semakin kecil jumlah epoch yang dihasilkan sehingga pola lebih cepat dikenali.

c. Pelatihan adaline akan efektif dalam mengenali pola huruf "P" jika menggunakan fungsi aktivasi bipolar.

d. Ketika nilai $\Delta \mathrm{Wi}<$ toleransi atau $\Delta \mathrm{Wi}>$ toleransi bahkan $\Delta \mathrm{Wi}=$ toleransi, bukan menjadi acuan dalam menemukan pola. Acuannya adalah dengan menyesuaikan nilai $\Delta \mathrm{Wi}<$ toleransi dan dihitung pada tabel kesimpulan atau setelah pelatihan adaline.

\section{DAFTAR PUSTAKA}

[1]. Suyanto. 2014. Artificial Intelligence (Searching, Reasoning, Planning, Learning) Revisi Kedua. Bandung: Informatika.

[2]. David. 2014. Sistem Pakar untuk Diagnosa Penyakit Ginjal dengan Jaringan Saraf Tiruan Adaline, in Proc. KNSI 2014, 7-8 November 2015.

[3]. Fadlisyah. 2013. Sistem Pendeteksian Wajah pada Video menggunakan Jaringan Adaptive Linier Neuron (ADALINE). TECHSI, 2 (1): 125:138.

[4]. Suhardi, Iwan. 2007. Evaluasi Pengaruh Fungsi Aktivasi dan Parameter Kemiringannya terhadap Unjuk Kerja Pengenalan Jaringan Syaraf Tiruan. Ilmiah Semesta Teknika, 10(1): 53-68.

[5]. Ihsan, Boy \& Sukma, Dian Y. 2017. Pengaruh Masukan dan Fungsi Aktivasi Terhadap Kecepatan Pelatihan Jaringan Syaraf Tiruan (JST) Modular sebagai Klasifikasi dan Estimasi Lokasi Gangguan pada Saluran Distribusi Bawah Tanah PT. Pertamina RU II Dumai. FTEKNIK, 4(1). 